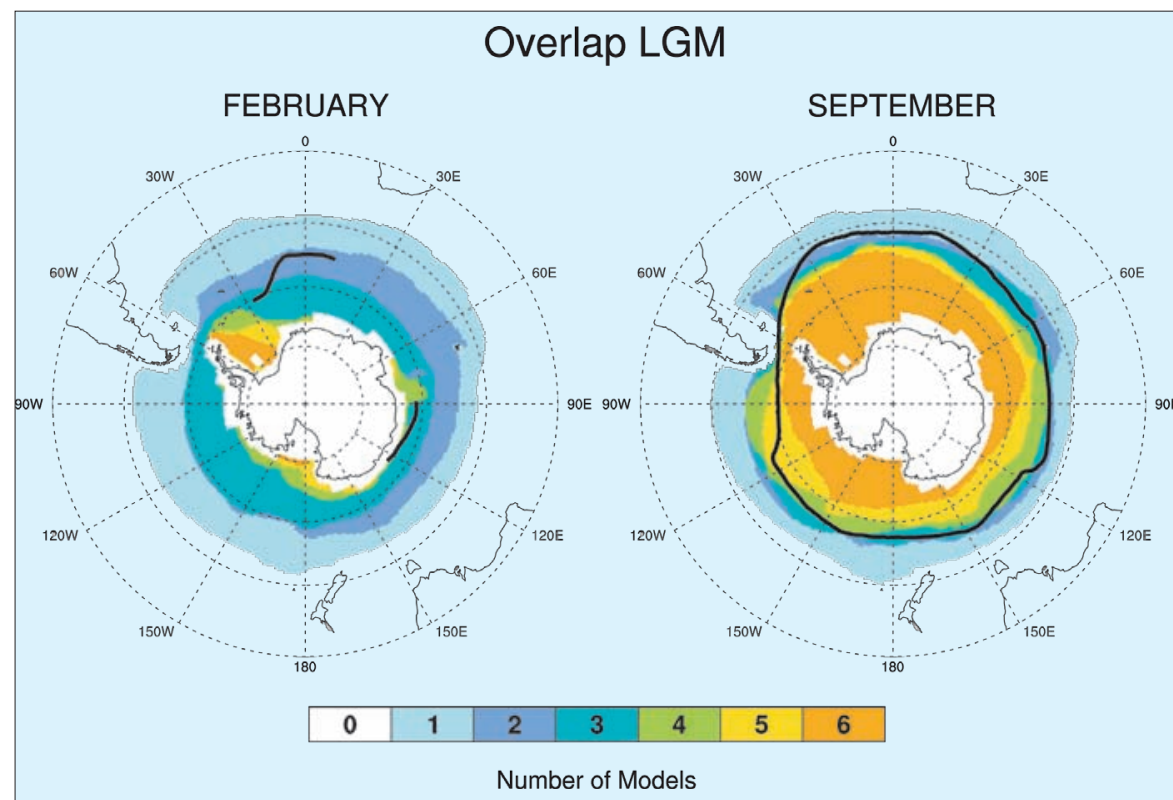

Figure 2: LGM sea ice distribution in the southern hemisphere simulated by PMIP2 models for February and September. For each grid cell, the figure indicates the number of models that simulate at least $15 \%$ of the area covered by sea ice. The proxy reconstructions of sea-ice edge (black lines) are from Gersonde et al. (2005)

feedbacks (Holland et al., 2001). This complexity is also highlighted by these PMIP2 results, where models show a large range of sea ice and associated ocean circulation responses to LGM forcing. Climate model simulations combined with proxy reconstructions have shown that LGM sea ice and ocean stratification can provide additional constraints on interpretation of the LGM Atlantic meridional overturning (Shin et al., 2003; Otto-Bliesner et al., 2007). LGM sea ice extent has been shown to be important in modulating the atmosphereocean interactions and water mass formation in the subpolar North Atlantic. The cold, salty Antarctic bottom waters at LGM form in coastal leads and just equatorward of permanent sea ice cover, due to brine rejection during sea ice production. Additionally, the suppression of air-sea gas exchange due to glacial sea ice expansion in the Southern Ocean has been suggested to play a possible role in regulating past atmospheric $\mathrm{CO}_{2}$ (Morales Maqueda and Rahmstorf, 2002; Stephens and Keeling, 2000).

Further information on the models discussed can be found at www.pages-igbp.org/products/newsletter/ref2008_2.html. Details on PMIP2 can be found at http://pmip2.Isce.ipsl.fr

\section{Acknowledgements}

We acknowledge the international modeling groups for providing their data for analysis, and the Laboratoire des Sciences du Climat et de l'Environnement for collecting and archiving the model data. The PMIP2/MOTIF Data Archive is supported by CEA, CNRS, the EU project MOTIF and the Programme National d'Etude de la Dynamique du Climat. Funding for NCAR and this research was provided by NSF.

\section{References}

Adkins, J.F., Mclntyre, K. and Schrag, D.P., 2002: The salinity, temperature, and $\delta^{18} 0$ of the glacial deep ocean, Science, 298: 1769-1773.

Braconnot, P. et al., 2007: Results of the PMIP2 coupled simulations of the mid-Holocene and Last Glacial Maximum. Part 1: experiments and large scale features, Climate of the Past, 3: 261-277.

Crosta, X., 2007: Late Quaternary Antarctic sea-ice history: Evidence from deep-sea sediments, PAGES News, 15(2): 13-14.

Gersonde, R, Crosta, X, Abelmann, A and Armand, L, 2005. Seasurface temperature and sea ice distribution of the Southern Ocean at the EPILOG Last Glacial Maximum - a circum-Antarctic view based on siliceous microfossil records, Quaternary Science Reviews, 24: 869-896.

Otto-Bliesner, B.L., Hewitt, C.D., Marchitto, T.M., Brady, E., Abe-Ouchi, A., Crucifix, M., Murakami, S. and Weber, S.L., 2007: Last Glacial Maximum ocean thermohaline circulation: PMIP2model intercomparisons and data constraints, Geophysical Research Letters, 34: L12706, doi:10.1029/2007GL029475.

For full references please consult:

www.pages-igbp.org/products/newsletter/ref2008_2.html

\title{
Are paleo-proxy data helpful for constraining future climate change?
}

Thomas Schneider von Deimling, H. Held, A. Ganopolski and S. Rahmstorf

Potsdam Institute for Climate Impact Research, Germany; schneider@pik-potsdam.de

How sensitive is our climate system to $\mathrm{CO}_{2}$ ? This is a key issue in a world of rising greenhouse gas concentrations. Estimating the temperature sensitivity of the Earth to changes in atmospheric $\mathrm{CO}_{2}$ has therefore been the subject of intensive research. Yet, uncertainty in our knowledge of this sensitivity is still large-as expressed by the broad $2-4.5^{\circ} \mathrm{C}$ range of climate sensitivity $\left(\Delta \mathrm{T}_{2 \mathrm{x}}\right)$ estimates (Meehl et al., 2007). Commonly $\Delta \mathrm{T}_{2 \mathrm{x}}$ is defined as the equilibrium global-mean temperature change for doubling the pre-industrial $\mathrm{CO}_{2}$ concentration. The direct radiative effect is a warming by $1^{\circ} \mathrm{C}$ but what makes the total warming uncertain is the strength of the fast climatic feedbacks - mainly ice-albedo, water vapor, lapse rate and cloud feedback. Here, we discuss how paleo-data can be used to reduce uncertainty in the range of $\Delta \mathrm{T}_{2 \mathrm{x}}$.

One way to compute climate sensitivity is to use climate models that calculate the feedbacks and thus $\Delta \mathrm{T}_{2 \times}$. Another ap- proach is to use the observed response of the climate system to constrain climate sensitivity. Studies using the climate signal provided by the instrumental record of the past 100-150 years were unable to rule out $\Delta \mathrm{T}_{2 \mathrm{x}}$ values above the IPCC range (Meehl et al., 2007). Unless we wait for the climate change signal to become much stronger, it will not be possible to greatly reduce uncertainty in $\Delta T_{2 x}$ in this way. A way out of this dilemma may be the use of paleo-data, which contain information on how sensitively the climate system has responded in the past to a radiative perturbation.

The three critical conditions for the success of this approach are: (1) a sufficiently large climate response in order to separate the signal from climatic noise, and sufficiently accurate data describing both (2) the climate change and (3) the forcing of this climate change. A promising candidate is the climate of the Last Glacial Maximum (LGM; 21 kyr BP), a time period that was on global average $4-7{ }^{\circ} \mathrm{C}$ colder than today (Schneider von Deimling et al., 2006a) with an abundance of good data on the forcing and the temperature distribution.

The observed response, seen through past climate changes, can be used in two ways for inferring $\Delta \mathrm{T}_{2 \mathrm{x}}$ :

(1) The ratio of past temperature change to forcing is estimated based on data and is then taken as a measure for the temperature response to doubling of $\mathrm{CO}_{2}$ (paleo-calibration, Covey et al., 1996). This approach assumes that the strength of the climate feedbacks inferred from the past can be taken as a direct measure for $\Delta T_{2 x^{*}}$ As the past is not a perfect analog for the future (e.g., the spatially inhomogeneous glacial forcing differs from the homogeneous $2 \mathrm{xCO}_{2}$ forcing), this assumption may be questionable.

(2) Using paleo-data in conjunction with climate models to constrain model 
parameters. We will refer to this approach, which estimates $\Delta T_{2 x}$ without assuming a perfect past-future analog, as the CMD (Constraining Models by Data) approach. Required for this are models able to simulate paleoclimates and present climate based on different boundary conditions without altering model parameters. Such models are used to simulate the temperature response of the climate system following a large radiative perturbation (e.g., as caused by prescribing LGM boundary conditions). The paleo-data are used to sort out those models that are overly sensitive or not sensitive enough. We can then base our estimate of $\Delta T_{2 x}$ on those models that have successfully simulated the LGM cooling (or other paleoclimates).

\section{Constraining climate sensitivity by LGM ensemble simulations}

We tested the CMD approach for estimating $\Delta \mathrm{T}_{2 \mathrm{x}}$ using a fully-coupled model of intermediate complexity (CLIMBER-2, Petoukhov et al., 2000). With an ensemble of 1000 model versions we calculated the present-day climate state, LGM cooling and $2 \mathrm{xCO}_{2}$ warming for all model versions (Schneider von Deimling et al., 2006b). A clear link between simulated $2 \times \mathrm{CO}_{2}$ warming and LGM cooling emerged in our model-ensemble: models with a high $\Delta \mathrm{T}_{2 x}$ also revealed a pronounced glacial cooling. By comparing the simulated present-day climate to data, we could discard a set of model versions, as they were inconsistent with the data, but the model versions that survived this test of model performance still showed a rather large range of $\Delta T_{2 x^{*}}$ However, using LGM data from tropical sea surface temperature regions and Antarctica, high sensitivity models could be rejected as being unrealistic (they simulated a LGM climate too cold). Accounting for uncertainty in the model parameters and in the paleo-proxies, the CMD approach allowed us to reject model versions with $\Delta \mathrm{T}_{2 \mathrm{x}}$ values above about $4^{\circ} \mathrm{C}$ (Fig. 1).

A crucial issue regarding the robustness of such an estimate is whether we have underestimated structural model uncertainty: what would have been the outcome of this analysis using a set of structurally different climate models? Applying somewhat different boundary conditions, Annan et al. (2005) performed a similar experiment based on a GCM ensemble (neglecting ocean dynamics and the forcing by glacial dust and vegetation) and inferred a weaker link between past cooling and future warming, resulting in a larger uncertainty estimate of $\Delta \mathrm{T}_{2 x}$. The impact of model structure on estimating $\Delta T_{2 x}$ is the most difficult type of uncertainty to quantify. More model studies that have performed comparable experiments would be helpful in this regard.

\section{Climate state dependency of climate feedbacks}

The strength of climate feedbacks $(\Lambda)$ depends, to a certain extent, on the climate state (e.g., a larger sea-ice and snow albedo feedback might operate in a colder climate than in a warmer one). As a consequence, linear extrapolation on $\Delta T_{2 x}$ from the LGM may be unreliable and the CMD approach should be used because climate models allow for the explicit simulation of the dependency of $\Lambda$ on the climate state.

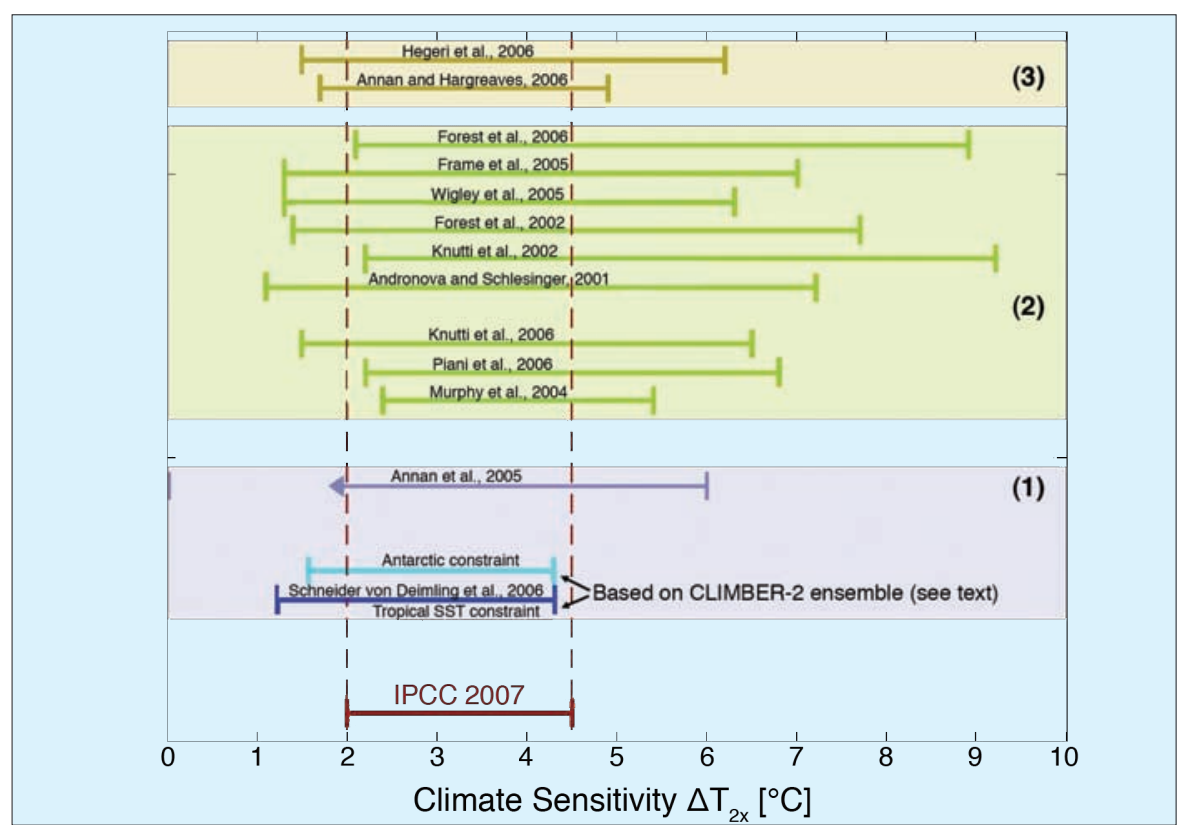

Figure 1: Model-based estimates of climate sensitivity (most intervals represent 90\% confidence levels, IPCC estimate is based on individual AR4 model results, Annan et al. (2005) do not provide a lower bound). $\Delta T_{2 x}$ ranges were constrained using (1) LGM proxy-data, (2) instrumental data, and (3) by combining paleo and instrumental data. A more extensive overview of studies having constrained the range of $\Delta T_{2 x}$ by paleo or instrumental data is presented by Edwards et al. (2007)
Yet, so far this state dependency of $\Lambda$ between the LGM and $2 \mathrm{xCO}_{2}$ climate has not been captured consistently among climate models (Crucifix, 2006; Hargreaves et al., 2007) and $\Delta \mathrm{T}_{2 \mathrm{x}}$ estimates inferred by such an approach depend to a certain extent on the model used. This is an uncomfortable situation for the prospect of using paleodata from a colder climate for constraining future warming. Further analyses are needed to better understand to what extent the current model discrepancy in the simulated feedback characteristics stems from different model physics, and to what extent from the method of analyzing the feedbacks. One explanation for discrepancies of simulated LGM characteristics could be that some models have not been run long enough to reach full equilibrium.

So far only a few state-of-the-art climate models have performed an LGM simulation experiment. It remains to be seen whether climate models with a $\Delta \mathrm{T}_{2 \mathrm{x}}$ well outside the IPCC range can simulate a LGM cooling consistently with paleo-evidence. The LGM climate provides a promising test of model sensitivity that is worth applying to a much larger set of climate models.

Further progress in narrowing the range of $\Delta T_{2 x}$ might also come from using paleo-constraints from warm periods. This could be valuable additional information, as a warmer climate can be considered a better analog for future climate change. One problem with paleo-data from a warmer world, however, is that they range farther back in time and uncertainties both in forcing and climate response are large. Reducing those uncertainties is especially promising for inferring better-constrained estimates of $\Delta \mathrm{T}_{2 \mathrm{x}}$ using the CMD approach as outlined here.

\section{Acknowledgements}

This work was supported by the Deutsche Forschungsgemeinschaft (research grant RA 977/1-1).

\section{References}

Annan, J., Hargreaves, J., Ohgaito, R., Abe-Ouchi, A. and Emori, S., 2005 Efficiently Constraining Climate Sensitivity with Ensembles of Paleoclimate Simulations, SOLA, 1: 181-184.

Edwards, T.L., Crucifix, M. and Harrison, S.P., 2007: Using the past to constrain the future: how the palaeorecord can improve estimates of global warming, Progress in Physical Geography, 31(5): 481-500.

Hargreaves, J.C., Abe-Ouchi, A. and Annan, J.D., 2007: Linking glacial and future climates through an ensemble of GCM simulations, Climate of the Past, $3(1): 77-87$.

Schneider von Deimling, T., Ganopolski, A., Held, H. and Rahmstorf, S., 2006a: How cold was the Last Glacial Maximum?, Geophysical Research Letters, 33(14): doi:10.1029/2006GL026484.

Schneider von Deimling, T., Held, H., Ganopolski, A. and Rahmstorf, S., 2006b: Climate sensitivity estimated from ensemble simulations of glacial climate, Climate Dynamics, 27(2-3): 149-163.

For full references please consult:

www.pages-igbp.org/products/newsletter/ref2008_2.html 